increasing the risk of heatstroke. ${ }^{89}$ The explanation proposed here does not preclude these possibilities. Indeed, infection is a major cause of both pyrexia and decreased arousal due to cytokine production. Thus, a number of these factors could act together to bring about a fatal outcome.

1 Fleming PJ, Gilbert R, Azaz Y, Berry PJ, Rudd PT, Stewar $A$, et al. Interaction between bedding and sleeping position in sudden infant death syndrome: a population based case control study. BMF 1990;301:85-9.

2 Engelberts AC, de Jonge GA. Choice of sleeping position for infants: possible association with cot death. Arch Dis Child 1990;65:462-7.
3 Taylor BJ. A review of epidemiological studies of sudden nfant death syndrome in Southern New Zealand. $\mathcal{F}$ Paediat Child Health 1991;27:344-8.

4 Morris JA, Haran D, Smith A. Hypothesis: common bacterial toxins are a possible cause of the sudden infant death syndrome. Med Hypotheses 1987;22:211-22.

5 Morris JA. Sudden infant death syndrome. BMF 1989;298:

6 Telford DR, Morris JA, Hughes P, Conway AR, Lee S, Barson AR, et al. The nasopharyngeal bacterial flora in sudden infant death syndrome. F Infect 1989;18:125-30.

7 McKendrick N, Drucker DB, Morris JA, Telford DR, Barson AJ, Oppenheim BA, et al. Bacterial toxins: a possible cause AJ, Oppenheim BA, et al. Bacterial toxins: a

8 Nelson EAS, Taylor BJ, Weatherall IL. Sleeping position and infant bedding may predispose to hyperthermia and the sudden infant death syndrome. Lancet 1989;i:199-200.

9 Ponsonby A-L, Dwyer T, Gibbons LE, Cochrane JA, Wang Y-G. Factors potentiating the risk of sudden infant death syndrome associated with the prone position. $N \mathrm{Engl} F \mathrm{Med}$ 1993;329:376-82

\title{
Nosocomial empyema caused by Clostridium difficile
}

\author{
A J H Simpson, S S Das, S Tabaqchali
}

\begin{abstract}
Pleural infection with Clostridium difficile is extremely rare. A case of nosocomial empyema following chest drain insertion in a 46 year old man is described. The potential of $C$ difficile to cause extra-intestinal infections should be recognised and its isolation from other sites should not be ignored.
\end{abstract}

(f Clin Pathol 1996;49:172-173)

Keywords: Clostridium difficile, empyema, nosocomial infection.

\section{Case report}

A 46 year old man was transferred from another hospital to St Bartholomew's Hospital, London, with a history of incessant atrial tachycardia secondary to alcoholic cardiomyopathy. Following admission, his tachycardia was treated and stabilised with digoxin $0.25 \mathrm{mg}$ per day and verapamil $80 \mathrm{mg}$ three times daily.

However, an admission chest $x$ ray revealed bilateral pleural effusions, larger on the right. There was increased shadowing and a cavitating mass in the left upper zone, with erosion of the first and second ribs anteriorly, suggestive of malignancy. There was no previous history of tuberculosis. The patient became pyrexial $\left(38^{\circ} \mathrm{C}\right) 24$ hours after admission, and after collection of blood cultures, was started on intravenous cefuroxime $750 \mathrm{mg}$ three times daily and oral erythromycin $500 \mathrm{mg}$ four times daily for a suspected chest infection. He had not previously received any antibiotics. No sputum samples were produced. A diagnostic tap of the right pleural effusion showed pus cells, but no bacteria, and was sterile on culture. A Ziehl-Neelsen (ZN) stain for acid/ alcohol fast bacilli was negative. The protein content was $37 \mathrm{~g} / 1$ and the glucose con- centration $6 \mathrm{mmol} / \mathrm{l}$. Cytology showed abundant polymorphs and reactive mesothelial cells, but no malignant cells. A rapid microagglutination test (RMAT) titre for Legionella pneumophila was less than 1:8.

The patient had a low grade fever over the following week and enlarging pleural effusions. His peripheral white cell count rose from $14.8 \times 10^{9} / 1$ to $19.6 \times 10^{9} / 1$. A pleural biopsy was performed, followed by right chest drain insertion and drainage of $1200 \mathrm{ml}$ blood stained fluid. Routine culture on blood, chocolate and cystine lactose electrolyte difficient (CLED) agar in an aerobic atmosphere with $5 \% \mathrm{CO}_{2}$ at $37^{\circ} \mathrm{C}$, and on blood agar anaerobically $(80 \%$ nitrogen, $10 \%$ hydrogen and $10 \% \mathrm{CO}_{2}$ ) at $37^{\circ} \mathrm{C}$, yielded no growth after 48 hours. $\mathrm{ZN}$ staining was again negative and all cultures for acid fast bacilli were negative at eight weeks. Tuberculin skin testing (1:1000) was negative.

Erythromycin was stopped and intravenous metronidazole added $(500 \mathrm{mg}$ three times daily), in case of aspiration post-cardioversion (attempted before admission to this hospital). Three days later, drainage from the chest drain ceased; a further pleural tap and biopsy was performed, producing thickened blood stained fluid. Cytology showed fibrinous material and many white cells consistent with an empyema. Direct Gram staining showed scanty large Gram positive rods and many neutrophils; anaerobic culture, as described above, revealed a pure growth of Clostridium difficile. Plates incubated aerobically showed no growth. No other specimens processed during this period showed evidence of Gram positive rods on staining, nor was $C$ difficile isolated from any other specimen, suggesting that laboratory contamination was extremely unlikely. The isolate was positive for toxin A using the Premier $C$ difficile Toxin A EIA kit (Meridian Diagnostics 
Europe, Milan, Italy). No stool samples were available for culture or direct toxin testing, but the patient did not have diarrhoea at any time during this admission.

The patient improved clinically over the next 72 hours, became apyrexial and was sent back to his referring hospital as his cardiological problems had been controlled. He received metronidazole for six days in total. The chest drain was removed prior to transfer, although he still had a right pleural effusion. He did not receive any further antibiotics. Appearances on chest $x$ ray film did not change further and it was concluded that these were caused by a chronic inflammatory process. The patient was stable six months after discharge and refused further investigation of his chest disease, including further pleural taps.

\section{Discussion}

Although $C$ difficile is well established as the major cause of pseudomembranous colitis (PMC), antibiotic associated colitis (AAC) and antibiotic associated diarrhoea (AAD), ${ }^{1-3}$ it is very rarely isolated from extraintestinal specimens, especially pleuropulmonary specimens, ${ }^{4}$ and is very rarely a cause of extraintestinal infection. ${ }^{5}$ Large outbreaks of AAC/AAD have occurred in hospitals ${ }^{6}$ and most cases of intestinal infection follow nosocomial acquisition of the organism. ${ }^{7}$ Such acquisition is likely in this patient, causing an empyema secondary to attempted drainage of a pleural effusion, although a primary aspiration pleuropneumonia cannot be excluded. The latter possibility seems less likely as the previous pleural fluid specimens were sterile, but we have no other satisfactory explanation for his chest disease. However, there were no cases of $C$ difficile associated diarrhoea on the same ward during his stay in this hospital.

Isolation of $C$ difficile from extraintestinal sites is frequently of little significance, ${ }^{5}$ but in this case isolation in pure culture and the response to aspiration and treatment with metronidazole suggest a pathogenetic role.
Risk factors for $C$ difficile associated intestinal disease include prior use of antibiotics, with the elderly and those with serious underlying conditions additionally predisposed. ${ }^{2}$ The number of reported cases of pleuropulmonary infection due to $C$ difficile is insufficient to draw reliable conclusions about risk factors for this disease, but in this case the patient had been receiving broad spectrum antibiotics.

Pleuropulmonary infections with other clostridial species, usually $C$ perfringens, have been reported occasionally. ${ }^{8}$ Very few cases of pleural infection with $C$ difficile have been reported, the first two cases being described in $1962 .{ }^{9}$

Pleural infections caused by clostridial species seem to behave clinically like empyemas due to other causes. ${ }^{10}$ In this case the process seems to have been relatively benign, assuming that this was a secondary infection and not the cause of the patient's underlying chest disease.

We suggest that isolation of $C$ difficile from extraintestinal sites should not be ignored and that its recognition as a nosocomial pathogen be extended beyond its role in AAD and PMC.

We thank Dr A W Nathan for permission to report this case.

1 Bartlett JG. Clostridium difficile: clinical considerations. Rev Infect Dis 1990;12(Suppl 2):S243-51.

2 Tabaqchali S, Jumaa P. Diagnosis and management of Clostridium difficile infection. BMf 1995;310:1375-80.

Kelly CP, Pothoulakis C, LaMont JT. Clostridium difficile Kelly CP, Pothoulakis C, LaMont JT. Clo
colitis. N Eng $\mathcal{f}$ Med 1994;330:257-62.

4 Marina M, Strong CA, Civen R, Molitoris E, Finegold SM. Bacteriology of anaerobic pleuropulmonary infections: preliminary report. Clin Infect Dis 1993;16(Suppl 4):S25662.

5 Levett PN. Clostridium difficile in habitats other than the human gastro-intestinal tract. F Infect 1986;12:253-63.

6 Cartmill TDI, Panigrahi H, Worsley MA, McCann DC, Nice CN, Keith E. Management and control of a large Infect $1994 ; 27: 1-15$. Infect 1994;27:1-15.

Heard SR, O'Farrell S, Holland D, Crook S, Barnett MJ, Tabaqchali $S$. The epidemiology of Clostridium difficile infection with use of a typing scheme: nosocomial acquisition and cross infection among immunocompromised patients. F Infect Dis 1986;153:159-62.

8 Lorber B. Gas gangrene and other Clostridium-associated diseases. In: Mandell GL, Bennett JE, Dolin R, eds. Mandell, Douglas and Bennett's Principles and practice of infectious diseases. 4th edn. New York: Churchill Livingstone; 1994:2182-95.

9 Smith LDS, King EO. Occurrence of Clostridium difficile in infections of man. $\mathcal{F}$ Bacteriol 1962;84:65-7.

10 Spagnuolo PJ, Payne VD. Clostridial pleuropulmonary infection. Chest 1980;78:622-5.

\title{
Gastroenteritis caused by Aeromonas trota in a child
}

\author{
J Reina, A Lopez
}

Clinical Microbiology Service, University Hospital Son Dureta, Universitat Illes Balears (UIB), 07014Palma de Mallorca, Spain

J Reina

A Lopez

Correspondence to: Dr Jordi Reina.

Accepted for publication 5 September 1995

\author{
Abstract \\ A case of acute diarrhoea caused by Aero- \\ monas trota (formerly HG 13 group) in a \\ Spanish child is reported. The strain was \\ isolated in the faeces using the CIN agar \\ (cefsulodin-irgasan-novobiocin) culture \\ media. The strain was initially identified \\ as $A$ sobria by the commercial GNI card
}

and API 20E biochemical systems. The strain was, however, VogesProskauer and sucrose negative, so complementary tests of cellobiose fermentation and gluconate oxidation were performed. These tests, together with the strain susceptibility to ampicillin (MIC $1 \mu \mathrm{g} / \mathrm{ml}$ ) and carbenicillin (MIC $<16 \mu \mathrm{g} / \mathrm{ml}$ ) led to the final iden- 